\title{
Prevalence of tuberculosis respiratory symptoms and associated factors in the indigenous populations of Paraguay (2012)
}

\author{
Sarita Aguirre', Celia Martínez Cuellar², María Belén Herrero ${ }^{3}$, Gustavo Chamorro Cortesi ${ }^{4}$, \\ Nilda Gimenez de Romero ${ }^{4}$, Mirian Alvarez ${ }^{5}$, Jose Ueleres Braga ${ }^{6,7} /+$
}

\author{
'Ministry of Public Health and Social Welfare of Paraguay, Tuberculosis Control Program, Asunción, Paraguay \\ ${ }^{2}$ Universidad Nacional de Asunción, Facultad de Ciencias Médicas, Asunción, Paraguay \\ ${ }^{3}$ Facultad Latinoamericana de Ciencias Sociales, Department of International Relations, Buenos Aires, Argentina \\ ${ }^{4}$ Ministry of Public Health and Social Welfare of Paraguay, Central Public Health Laboratory, Asunción, Paraguay \\ ${ }^{5}$ Ministry of Public Health and Social Welfare of Paraguay, Department of Statistics of the Tuberculosis Control Program, Asunción, Paraguay \\ ${ }^{6}$ Fundação Oswaldo Cruz-Fiocruz, Escola Nacional de Saúde Pública, Departamento de Epidemiologia e Métodos Quantitativos, Rio de Janeiro, RJ, Brasil \\ ${ }^{7}$ Universidade do Estado do Rio de Janeiro, Instituto de Medicina Social, Departamento de Epidemiologia, Rio de Janeiro, RJ, Brasil
}

BACKGROUND The prevalence of respiratory symptoms and confirmed tuberculosis (TB) among indigenous groups in Paraguay is unknown.

METHODS This study assessed the prevalence of respiratory symptoms, confirmed pulmonary TB, and associated socio-economic factors among indigenous Paraguayan populations. Indigenous persons residing in selected communities were included in the study. A total of 24,352 participants were interviewed at home between October and December 2012. Respiratory symptomatic individuals were defined as those with respiratory symptoms of TB. A hierarchical Poisson regression analysis was performed with four levels: individual characteristics, living conditions and environmental characteristics, source of food, and type of nutrition.

FINDINGS In this study, 1,383 participants had respiratory symptoms (5.7\%), but only 10 had culture-confirmed TB (41/100,000 inhabitants). The small number of cases did not allow evaluation of the risk factors for TB. Age older than 37 years was associated with a two-fold increased risk of symptoms. Female sex; family history of TB; type of housing; home heating; a lack of hunting, fishing, or purchasing food; and a lack of vegetable consumption were also associated with the presence of symptoms. A lack of cereal consumption had a protective effect. Members of the Ayoreo or Manjui ethnic groups had a three-fold increased risk of symptoms.

MAIN CONCLUSION Individual characteristics, dietary habits, and belonging to specific ethnic groups were associated with respiratory symptoms.

Key words: pulmonary tuberculosis - population groups - cross-sectional studies - risk factors

Despite being a curable and preventable disease, tuberculosis (TB) remains a significant public health issue worldwide. The determinants of TB epidemiology include socioeconomic inequality, delayed diagnosis, and lack of social support for the care of sick individuals (Hargreaves et al. 2011). TB largely affects the vulnerable sections of the population, including indigenous populations (AFN 2009, Tollefson et al. 2013).

An approximate population of 370,000,000 indigenous persons worldwide comprises $5 \%$ of the global population (UN 2012). While there is evidence to suggest that the burden of TB increases considerably among the indigenous populations (Fanning 1999, Fitzgerald et al. 2000, Das et al. 2006, Barry \& Konstantinos 2009, CDC 2010), the current global burden of TB remains unknown (Hoeppner \& Marciniuk 2000, Culqui et al. 2010, Tollefson et al. 2013). The Stop TB Initiative highlighted the need to improve surveillance in indigenous villages in order to assess the burden of TB among these populations (AFN 2009).

doi: 10.1590/0074-02760160443

+ Corresponding author: ueleres@gmail.com

Received 4 October 2016

Accepted 20 March 2017
Ten percent of the population in Latin America is indigenous (Culqui et al. 2010). The majority suffer discrimination and live in isolation and poverty. TB in these indigenous populations is associated with high poverty, migration, marginalisation, lack of territorial rootedness, environment destruction, and unmet basic needs (Culqui et al. 2010, Lopez et al. 2013). Poor living conditions increase the susceptibility to illness in these populations, and there are often language, geographical, and cultural barriers that lead to a delayed diagnosis of TB, which results in the delayed identification of transmission sources within the community and an increased risk of new cases (Culqui et al. 2010, Lopez et al. 2013, Tollefson et al. 2013).

According to the 2002 Census, there are 20 ethnic groups in Paraguay, which constitute $1.7 \%$ of the national population (DGEEC 2012). Based on the results of the 2012 Survey of Indigenous Households, approximately 112,800 persons belong to indigenous communities (DGEEC 2012).

$\mathrm{TB}$ is an endemic disease that constitutes a serious public health problem, primarily affecting the groups with the greatest levels of poverty in Paraguay (Lopez et al. 2013). Approximately 1,400 cases of pulmonary TB-positive smears are detected annually (24 cases per 100,000), while more than 200 cases are detected annually in the indigenous population, corresponding to 180 cases per 100,000 persons (http://vigisalud.gov.py/index. php/programa-nacional-de-control-de-la-tuberculosis/). 
The estimated incidence of respiratory symptoms (RS) and the prevalence of TB among the indigenous populations of Paraguay are not known; thus, this study primarily aims to fill this knowledge gap. The objective of this study was to assess the prevalence of RS and pulmonary TB among the indigenous population of Paraguay and to identify the major socio-economic factors associated with TB in this population.

\section{SUBJECTS AND METHODS}

The study group consisted of the indigenous population residing habitually or permanently in indigenous communities nationwide. Any person living in a community for more than six months prior to the initial visit and who had not travelled outside the community for more than three of the previous six months was considered a habitual resident of the community. The inclusion criteria were as follows: persons belonging to any indigenous group in Paraguay, habitual residence within the selected communities, and voluntary verbal consent to participate in the survey.

The participants were interviewed in their homes by interviewers from the National Program for Tuberculosis Control (NPTC) of Paraguay, using a structured questionnaire to collect the study data. A maximum of three visits was made. The questionnaire applied in the survey collected data on demographic, economic, and housing characteristics, as well as information on personal and family history of TB, access to health services, and TB-related symptoms. The survey was organised in four sections: population characteristics, housing characteristics, prevalence of TB, and knowledge of TB.

A pilot test including 42 residents of the Jukyty indigenous community (not included in the study) was performed before the commencement of the survey. The participants in this study were provided a special form of informed consent to request their agreement to participate in the interview, which ensured ethical safeguards in accordance with the principles established in the Declaration of Helsinki.

Individuals with RS were examined, and two sputum samples were collected following fasting. Direct bacilloscopic examination was performed in the health services laboratories that attend this community, and culture examination was performed in the central laboratory after storage and delivery according to the standards of the National Tuberculosis Control Program of Paraguay.

Sputum samples were sent to the laboratories located closest to the community. The fieldwork lasted seven weeks (October-December, 2012). The sampling design was multistep, stratified with simple random sampling within the strata, with 94 communities selected from among 584 existing indigenous communities. The sample size was based on a prevalence of $0.5 \%$, absolute error of $0.1 \%$, finite population of 117,528 inhabitants, and design effect of 1.5. Thus, the calculated sample size was 24,266 indigenous persons.

Individuals with RS were defined as those reporting the presence of RS related to TB (a cough lasting three or more weeks, coughing up blood, chest pain, or pain when breathing or coughing). Pulmonary TB was defined as the presence of respiratory symptoms with a positive culture (Lowenstein-Jensen method).
A hierarchical Poisson regression analysis was performed to identify associated factors. The four levels (dimensions) of the analysis and their respective independent variables were: (level 1) Individual characteristics - age $(<$ 38 years or $>38$ years), sex (male/female), education level [Educación Escolar Básica (EEB) Level 1, 2, or $\geq$ level 3]; (level 2) living conditions and environmental characteristics - family history of TB (yes/no); type of housing; type of toilet (flush toilet/other); home heating type (none/some heating); access to a television (yes/no); ownership of horse, donkey, ox (yes/no); main cooking method (wood/ other); (level 3) sourcing of food - personal garden (yes/ no); hunting or fishing (yes/no); purchase of foods (yes/ no); receipt of donations (yes/no); and (level 4) type of nutrition - vegetables (yes/no), cereals (yes/no), fruit (yes/ no), meat (yes/no), dairy products (yes/no). An "Ayoreo/ Manjui Ethnicity" variable was constructed, composed of the two ethnic groups with the highest prevalence of RS, and was included in the final multiple regression analysis.

The prevalence measures and their respective confidence intervals [95\% CI (confidence interval)] were calculated. The prevalence ratio (PR) was calculated for the putative factors associated with RS. A simple Poisson regression was used to assess the individual effect of the independent variables on RS. Variables that were significant in the simple regression model $(p<0.20)$ were included in the respective multiple regression models. A multiple Poisson regression analysis was performed for each level, controlling for potential confounding variables. Only significant variables $(p<0.05)$ for each of the models were incorporated into the final regression model. The final model included variables with a significance level of $\mathrm{p}<0.05$. All statistical procedures were performed using Stata version 11.0.

\section{RESULTS}

The interviewers visited 19 communities located across 13 departments. The survey included 24,352 people, 1,383 (5.7\%) of whom had RS. Of these, 10 participants were culture-confirmed as having TB (41 per 100,000 inhabitants). The limited number of confirmed TB cases prevented the study of the associated factors.

Analysis of individual characteristics (level 1) revealed the highest frequency of RS among those of Ayoreo and Manjui ethnicities (Table I). Persons aged 38 to 95 years and divorcees had the highest RS prevalence. The RS prevalence also differed according to the work status of the household head. The RS prevalence was higher among female sex and individuals with a higher education status and without a visible BCG scar (Table I).

Analysis of the living conditions and availability of goods and resources (level 2) revealed that RS were more frequent among participants with a family history of TB as well as among those living in makeshift housing, in houses roofed with wooden slats, or in houses with water tanks, no electricity, or with a deficient sanitary service and among those drinking untreated water, without electricity, or with deficient sanitary services. Significant differences were also observed among participants without a refrigerator, stove, phone, television, radio, or computer and without a means of transport or any heating system (Table II). 
TABLE I

Individual characteristics of the survey population, stratified according to respiratory symptoms (level 1), Paraguay, 2012

\begin{tabular}{|c|c|c|c|c|c|c|c|}
\hline & \multicolumn{6}{|c|}{ Respiratory symptomatic } & \multirow[b]{3}{*}{$\mathrm{p}$-value } \\
\hline & \multicolumn{2}{|c|}{ No } & \multicolumn{2}{|c|}{ Yes } & \multicolumn{2}{|c|}{ Total } & \\
\hline & $\mathrm{n}$ & $(\%)$ & $\mathrm{n}$ & $(\%)$ & $\mathrm{N}$ & $(\%)$ & \\
\hline \multicolumn{8}{|l|}{ Ethnic group } \\
\hline Aché & 131 & 91,6 & 12 & 8,4 & 143 & 100 & \\
\hline Angaité & 600 & 96,3 & 23 & 3,7 & 623 & 100 & \\
\hline Ava Guaraní & 3936 & 95,9 & 170 & 4,1 & 4106 & 100 & \\
\hline Ayoreo & 731 & 79,3 & 191 & 20,7 & 922 & 100 & \\
\hline Chamacoco Tomahoro & 95 & 100 & 0 & 0 & 95 & 100 & \\
\hline Chamacoco Yvytoso & 858 & 96,7 & 29 & 3,3 & 887 & 100 & \\
\hline Enxet & 671 & 94,1 & 42 & 5,9 & 713 & 100 & \\
\hline Guana & 22 & 95,7 & 1 & 4,3 & 23 & 100 & \\
\hline Guaraní Nandeva & 445 & 96,1 & 18 & 3,9 & 463 & 100 & \\
\hline Guaraní occidental & 944 & 97,6 & 23 & 2,4 & 967 & 100 & \\
\hline Lengua Enlhet Sur & 2568 & 95,4 & 124 & 4,6 & 2692 & 100 & \\
\hline Maká & 784 & 95,7 & 35 & 4,3 & 819 & 100 & \\
\hline Manjui & 95 & 81,2 & 22 & 18,8 & 117 & 100 & \\
\hline Mbya & 1941 & 93,4 & 138 & 6,6 & 2079 & 100 & \\
\hline Nivaclé & 4347 & 93,7 & 291 & 6,3 & 4638 & 100 & \\
\hline Páî-Tavyterâ & 2712 & 93,4 & 191 & 6,6 & 2903 & 100 & \\
\hline Sanapaná & 280 & 97,2 & 8 & 2,8 & 288 & 100 & \\
\hline Toba Maskoy & 366 & 95,8 & 16 & 4,2 & 382 & 100 & \\
\hline Toba-Qom & 882 & 97,7 & 21 & 2,3 & 903 & 100 & \\
\hline Total & 22408 & 94,3 & 1355 & 5,7 & 23763 & 100 & $<0.001$ \\
\hline \multicolumn{8}{|l|}{ Age (year groups) } \\
\hline 0-37 years & 18490 & 95,4 & 881 & 4,6 & 19371 & 100 & \\
\hline $38-95$ years & 4487 & 89,9 & 502 & 10,1 & 4989 & 100 & \\
\hline Total & 22977 & 94,3 & 1383 & 5,7 & 23062 & 100 & $<0.001$ \\
\hline \multicolumn{8}{|l|}{ Sex } \\
\hline Male & 11835 & 95,1 & 611 & 4,9 & 12446 & 100 & \\
\hline Female & 11080 & 93,5 & 771 & 6,5 & 11850 & 100 & \\
\hline Total & 22915 & 94,3 & 1382 & 5,7 & 24296 & 100 & $<0.001$ \\
\hline \multicolumn{8}{|l|}{ Civil status } \\
\hline Civil marriage & 2471 & 92,3 & 205 & 7,7 & 2676 & 100 & \\
\hline Traditional wedding & 2538 & 92,3 & 211 & 7,7 & 2749 & 100 & \\
\hline Separated & 279 & 94,6 & 16 & 5,4 & 295 & 100 & \\
\hline Divorced & 11 & 78,6 & 3 & 21,4 & 14 & 100 & \\
\hline Widower & 379 & 84 & 72 & 16 & 451 & 100 & \\
\hline Single & 13295 & 95,4 & 645 & 4,6 & 13940 & 100 & \\
\hline Cohabitation & 3726 & 94,4 & 220 & 5,6 & 3946 & 100 & \\
\hline Total & 22699 & 94,3 & 1372 & 5,7 & 24071 & 100 & $<0.001$ \\
\hline \multicolumn{8}{|l|}{ Education level } \\
\hline Up to EEB $1^{\circ}$ y $2^{\circ}$ level & 14088 & 94,8 & 768 & 5,2 & 14856 & 100 & \\
\hline EEB $3^{\circ}$ level or above & 8889 & 93,5 & 615 & 6,5 & 9504 & 100 & \\
\hline Total & 22977 & 94,3 & 1383 & 5,7 & 24360 & 100 & $<0.001$ \\
\hline \multicolumn{8}{|l|}{ Household head work status } \\
\hline Salaried & 1.123 & 93,7 & 76 & 6,3 & 1.199 & 100 & \\
\hline Laborer & 418 & 9,6 & 177 & 4,1 & 4.357 & 100 & \\
\hline Self employed & 16.161 & 93,9 & 1.053 & 6,1 & 17.214 & 100 & \\
\hline None & 1.449 & 95,1 & 75 & 4,9 & 1.524 & 100 & \\
\hline Total & 19.151 & 78,8 & 1.381 & 5,7 & 24.294 & 100 & $<0.001$ \\
\hline
\end{tabular}




\begin{tabular}{|c|c|c|c|c|c|c|c|}
\hline & \multicolumn{6}{|c|}{ Respiratory symptomatic } & \multirow[b]{3}{*}{ p-value } \\
\hline & \multicolumn{2}{|c|}{ No } & \multicolumn{2}{|c|}{ Yes } & \multicolumn{2}{|c|}{ Total } & \\
\hline & $\mathrm{n}$ & $(\%)$ & $\mathrm{n}$ & $(\%)$ & $\mathrm{N}$ & $(\%)$ & \\
\hline \multicolumn{8}{|c|}{ Visible BCG scar } \\
\hline Yes & 10810 & 92,5 & 876 & 7,5 & 11686 & 100 & \\
\hline No & 3398 & 91,3 & 324 & 8,7 & 3722 & 100 & \\
\hline Total & 14208 & 92,2 & 1200 & 11,6 & 15408 & 100 & 0,017 \\
\hline
\end{tabular}

Source: own elaboration.

Analysis of the modes of obtaining food and diet (levels 3 and 4 ) revealed that individuals with their own gardens had fewer RS. Conversely, RS were more frequently observed among participants who did not eat vegetables, meat, dairy, or fruit as well as among those with higher consumption of grain (Table III).

Univariate analysis showed that TB symptoms were associated with age, sex, educational level and family history of TB. Symptoms were also associated with the type of housing; availability of sanitary services; and the lack of a home heating system, personal garden, consumption of donated food and hunting or fishing, as well as the purchase of food. Diets without vegetables, meat and dairy, as well as the means used for cooking, were also positively associated with the presence of symptoms. Finally, diets that included cereals or fruit were also risk factors for the development of symptoms (Table IV).

The lack of a heating system and the use of a woodfired stove increased the risk for RS. The lack of access to a television, means of transport by animal and donated food were associated with an increased risk of RS (Table IV).

The final hierarchical analysis (Table IV) showed that age $>37$ years increased the risk of symptoms by nearly two-fold. Female sex and family history of TB were also risk factors. The following factors were associated with an increased risk of RS: type of housing and home heating; not hunting or fishing; not purchasing food; and not consuming vegetables. Conversely, lack of grain consumption was a protective factor. Finally, belonging to the Ayoreo or Manjui ethnic groups increased the risk of symptoms by three-fold.

\section{DISCUSSION}

The active identification of RS for the diagnosis of pulmonary TB is one of the most important tools from the perspective of public health. To our knowledge, this is the first study to estimate the prevalence of RS in an indigenous population in Paraguay and to address the burden of disease in this population.

The RS prevalence among indigenous communities in Paraguay in this study was 5.7\% (1,383 cases). A total of 10 cases of TB were found. These results are comparable to those of large-scale studies conducted in other Latin American countries. Peru has reported an RS prevalence of 5\% among the general population (Collazos et al. 2010). The estimated RS prevalence rates in two regions of Brazil are $5.7 \%$ and $4.8 \%$, respectively (Freitas et al. 2011). Finally, Colombia reported an RS prevalence of $3.6 \%$ (García et al. 2004). The importance of these findings is that a significant proportion of respiratory symptomatic individuals may be pulmonary TB cases. In a study carried out in Vaupés (Colombia) to examine the prevalence of RS and TB and its associated factors, the prevalence of RS was $14.3 \%$, with a 14 -fold increase in the risk of TB in participants with RS (García et al. 2004). García et al. (2004) reported that the prevalence of RS among the indigenous population was almost twice that among non-indigenous persons. This observation is consistent with a study in Colombia, which reported that indigenous populations are much more likely to develop TB than non-indigenous populations in the area due to their generally deficient nutritional states and overcrowded conditions (Henao et al. 1999). Similarly, we also observed that the indigenous population in the current study was at risk of having symptoms. Furthermore, the results of our study show that individuals of Ayoreo or Manjui ethnicity had more than three-fold increased risk of having symptoms.

The findings of our study also suggest that the indigenous populations with RS suffer the worst deprivation, suggesting that RS prevalence is a multidimensional problem involving different factors related to individual characteristics, living conditions, social characteristics specific to the surrounding environment, type of nutrition and access to certain material goods. This is consistent with a study by Muniyandi et al. (2007), which observed a higher prevalence of RS and TB among populations exposed to greater poverty.

Living in makeshift homes, without a heating system and without a system for cooking are criteria that increase the risk of symptoms. Most previous studies did not assess the association between these housing characteristics and the prevalence of RS within the community. However, our results are consistent with the findings of a study conducted in two cities in Colombia by Daza Arana (2013), which concluded that living in poor housing with inadequate ventilation and in homes with roofs predominantly made of waste material were associated with an increased prevalence of RS (Moreno \& Peña 2010). In addition, research conducted in Bucaramanga, Colombia (Nóbrega et al. 2010) found that RS was associated with households with no windows, with occupancies $>3$ 
TABLE II

Living conditions and availability of goods and resources of the surveyed population, stratified according to respiratory symptoms (level 2), Paraguay, 2012

\begin{tabular}{|c|c|c|c|c|c|c|c|}
\hline & \multicolumn{6}{|c|}{ Respiratory symptomatic } & \multirow[b]{3}{*}{ p-value } \\
\hline & \multicolumn{2}{|c|}{ No } & \multicolumn{2}{|c|}{ Yes } & \multicolumn{2}{|c|}{ Total } & \\
\hline & $\mathrm{n}$ & $(\%)$ & $\mathrm{n}$ & $(\%)$ & $\mathrm{N}$ & $(\%)$ & \\
\hline \multicolumn{8}{|l|}{ Family history of TB } \\
\hline No & 20.705 & 94,7 & 1.149 & 5,3 & 21.854 & 100 & \\
\hline Yes & 643 & 81,8 & 143 & 18,2 & 786 & 100 & \\
\hline Total & 21.348 & 94,3 & 1.292 & 5,7 & 22.640 & 100 & $<0.001$ \\
\hline \multicolumn{8}{|l|}{ Type of housing } \\
\hline House / Rancho & 20.305 & 94,6 & 1148 & 5,4 & 21.453 & 100 & \\
\hline Makeshift shelter & 2626 & 91,8 & 234 & 8,2 & 2.860 & 100 & \\
\hline Total & 22.931 & 94,3 & 1382 & 5,7 & 24.313 & 100 & $<0.001$ \\
\hline \multicolumn{8}{|l|}{ Type of roofing } \\
\hline Tile & 970 & 94,3 & 59 & 5,7 & 1.029 & 100 & \\
\hline Straw & 5.818 & 94,4 & 344 & 5,6 & 6.162 & 100 & \\
\hline Asbestos cement (Eternit) & 1.926 & 95,4 & 93 & 4,6 & 2.019 & 100 & \\
\hline Zinc sheet & 12.779 & 94 & 818 & 6 & 13.597 & 100 & \\
\hline Wooden tablet & 81 & 93,1 & 6 & 6,9 & 87 & 100 & \\
\hline Reinforced concrete, earthenware & 27 & 90 & 3 & 10 & 30 & 100 & \\
\hline Palm trunk & 896 & 96,4 & 33 & 3,6 & 929 & 100 & \\
\hline Cardboard, rubber, packaging timber & 426 & 94 & 27 & 6 & 453 & 100 & \\
\hline Total & 22.923 & 94,3 & 1.383 & 5,7 & 24.306 & 100 & 0.021 \\
\hline \multicolumn{8}{|l|}{ Main source of water } \\
\hline ESSAP & 1.573 & 95,4 & 75 & 4,6 & 1.648 & 100 & \\
\hline Private Network (aguatería) & 199 & 94,8 & 11 & 5,2 & 210 & 100 & \\
\hline Community Network (com.vecinal) & 2.155 & 95,5 & 101 & 4,5 & 2.256 & 100 & \\
\hline Artesian well & 1.574 & 94,2 & 97 & 5,8 & 1.671 & 100 & \\
\hline Common water well with curbstone with lid & 1.207 & 94,4 & 72 & 5,6 & 1.279 & 100 & \\
\hline Common water well with curbstone capless & 1.615 & 94,8 & 88 & 5,2 & 1.703 & 100 & \\
\hline Common water well without curbstone & 857 & 94,1 & 54 & 5,9 & 911 & 100 & \\
\hline Cistern & 7.041 & 93,1 & 524 & 6,9 & 7.565 & 100 & \\
\hline Tajamar, rising, river, stream & 5.675 & 94,7 & 319 & 5,3 & 5.994 & 100 & \\
\hline Australian tank & 72 & 96 & 3 & 4 & 75 & 100 & \\
\hline Water tank & 924 & 96,5 & 34 & 3,5 & 958 & 100 & \\
\hline Total & 22892 & 94,3 & 1.378 & 5,7 & 24.270 & 100 & $<0.001$ \\
\hline \multicolumn{8}{|l|}{ Treatment for drinking water } \\
\hline Filtered & 433 & 95,6 & 20 & 4,4 & 453 & 100 & \\
\hline Boiled & 460 & 95 & 24 & 5 & 484 & 100 & \\
\hline Treated with sodium hypochlorite & 1.652 & 95,5 & 78 & 4,5 & 1.730 & 100 & \\
\hline No treatment & 20.332 & 94,2 & 1.260 & 5,8 & 21.592 & 100 & \\
\hline Total & 22.877 & 94,3 & 1.382 & 5,7 & 24.259 & 100 & 0.066 \\
\hline \multicolumn{8}{|l|}{ Availability of electricity } \\
\hline Yes (ANDE) & 12.901 & 95,1 & 658 & 4,9 & 13.559 & 100 & \\
\hline Yes (Generated) & 262 & 94,6 & 15 & 5,4 & 277 & 100 & \\
\hline None & 9.752 & 93,2 & 710 & 6,8 & 10.462 & 100 & \\
\hline Total & 22.915 & 94,3 & 1.383 & 5,7 & 24.298 & 100 & $<0.001$ \\
\hline \multicolumn{8}{|l|}{ Type of health service } \\
\hline Bath water trawl (network/well) & 676 & 96,4 & 25 & 3,6 & 701 & 100 & \\
\hline Other (Community, stream, river) & 22301 & 94,3 & 1358 & 5,7 & 23659 & 100 & \\
\hline Total & 22.977 & 94,3 & 1.383 & 5,7 & 24.360 & 100 & 0.014 \\
\hline
\end{tabular}




\begin{tabular}{|c|c|c|c|c|c|c|c|}
\hline & \multicolumn{6}{|c|}{ Respiratory symptomatic } & \multirow[b]{3}{*}{$\mathrm{p}$-value } \\
\hline & \multicolumn{2}{|c|}{ No } & \multicolumn{2}{|c|}{ Yes } & \multicolumn{2}{|c|}{ Total } & \\
\hline & $\mathrm{n}$ & $(\%)$ & $\mathrm{n}$ & $(\%)$ & $\mathrm{N}$ & $(\%)$ & \\
\hline \multicolumn{8}{|l|}{ Type of waste disposal } \\
\hline Buried & 1.142 & 95,6 & 53 & 4,4 & 1.195 & 100 & \\
\hline burned & 14.223 & 94,6 & 808 & 5,4 & 15.031 & 100 & \\
\hline Thrown in water course & 94 & 96,9 & 3 & 3,1 & 97 & 100 & \\
\hline Thrown outdoors & 3.752 & 92,1 & 324 & 7,9 & 4.076 & 100 & \\
\hline Garbage collection & 3.719 & 95,1 & 193 & 4,9 & 3.912 & 100 & \\
\hline Total & 22.930 & 94,3 & 1.381 & 5,7 & 24.311 & 100 & $<0.001$ \\
\hline \multicolumn{8}{|l|}{ Type of home heating } \\
\hline None & 11650 & 93,5 & 809 & 6,5 & 12459 & 100 & \\
\hline Other & 11327 & 95,2 & 574 & 4,8 & 11901 & 100 & \\
\hline Total & 22977 & 94,3 & 1.383 & 5,7 & 24.360 & 100 & $<0.001$ \\
\hline \multicolumn{8}{|l|}{ Cooking methods } \\
\hline Firewood & 19096 & 94 & 1.222 & 6 & 20.318 & 100 & \\
\hline Other & 3881 & 96 & 161 & 4 & 4042 & 100 & \\
\hline Total & 22915 & 94,3 & 1.380 & 5,7 & 24.360 & 100 & $<0.001$ \\
\hline \multicolumn{8}{|l|}{ Access to a refrigerator } \\
\hline Yes & 5.060 & 96 & 212 & 4 & 5.272 & 100 & \\
\hline No & 15.492 & 93,5 & 1.082 & 6,5 & 16.574 & 100 & \\
\hline Total & 20.552 & 94,1 & 1.294 & 5,9 & 21.846 & 100 & $<0.001$ \\
\hline \multicolumn{8}{|l|}{ Access to a kitchen } \\
\hline Yes & 4.080 & 95,8 & 181 & 4,2 & 4.261 & 100 & \\
\hline No & 16.298 & 93,6 & 1.113 & 6,4 & 17.411 & 100 & \\
\hline Total & 20.378 & 94 & 1.294 & 6 & 21.672 & 100 & $<0.001$ \\
\hline \multicolumn{8}{|l|}{ Access to a cellphone } \\
\hline Yes & 13.799 & 94,7 & 768 & 5,3 & 14.567 & 100 & \\
\hline No & 7.953 & 93,5 & 551 & 6,5 & 8.504 & 100 & \\
\hline Total & 21.752 & 94,3 & 1.319 & 5,7 & 23.071 & 100 & $<0.001$ \\
\hline \multicolumn{8}{|l|}{ Access to a TV } \\
\hline Yes & 9.114 & 95,6 & 416 & 4,4 & 9.530 & 100 & \\
\hline No & 12.014 & 93,1 & 894 & 6,9 & 12.908 & 100 & \\
\hline Total & 21.128 & 94,2 & 1.310 & 5,8 & 22.438 & 100 & $<0.001$ \\
\hline \multicolumn{8}{|l|}{ Access to a radio } \\
\hline Yes & 16.328 & 94,5 & 956 & 5,5 & 17.284 & 100 & \\
\hline No & 5.472 & 93,8 & 364 & 6,2 & 5.836 & 100 & \\
\hline Total & 21.800 & 94,3 & 1.320 & 5,7 & 23.120 & 100 & 0.044 \\
\hline \multicolumn{8}{|c|}{ Access to a computer or notebook } \\
\hline Yes & 458 & 96,4 & 17 & 3,6 & 475 & 100 & \\
\hline No & 19.638 & 93,9 & 1.267 & 6,1 & 20.905 & 100 & \\
\hline Total & 20.096 & 94 & 1.284 & 6 & 21.380 & 100 & 0.024 \\
\hline \multicolumn{8}{|l|}{ Access to a car } \\
\hline Yes & 434 & 97,3 & 12 & 2,7 & 446 & 100 & \\
\hline No & 19.621 & 93,9 & 1.269 & 6,1 & 20.890 & 100 & \\
\hline Total & 20.055 & 94 & 1.281 & 6 & 21.336 & 100 & 0.003 \\
\hline \multicolumn{8}{|l|}{ Access to a motorcycle } \\
\hline Yes & 9.441 & 95,1 & 482 & 4,9 & 9.923 & 100 & \\
\hline No & 11.609 & 93,3 & 833 & 6,7 & 12.442 & 100 & \\
\hline Total & 21.050 & 94,1 & 1.315 & 5,9 & 22.365 & 100 & $<0.001$ \\
\hline \multicolumn{8}{|c|}{ Access to a horse, donkey, or ox } \\
\hline Yes & 870 & 96,6 & 31 & 3,4 & 901 & 100 & \\
\hline No & 19.251 & 93,9 & 1.250 & 6,1 & 20.501 & 100 & \\
\hline Total & 20.121 & 94 & 1.281 & 6 & 21.402 & 100 & 0.001 \\
\hline
\end{tabular}




\begin{tabular}{|c|c|c|c|c|c|c|c|}
\hline & \multicolumn{6}{|c|}{ Respiratory symptomatic } & \multirow[b]{3}{*}{ p-value } \\
\hline & \multicolumn{2}{|c|}{ No } & \multicolumn{2}{|c|}{ Yes } & \multicolumn{2}{|c|}{ Total } & \\
\hline & $\mathrm{n}$ & $(\%)$ & $\mathrm{n}$ & $(\%)$ & $\mathrm{N}$ & $(\%)$ & \\
\hline \multicolumn{8}{|c|}{ Access to a bicycle } \\
\hline Yes & 7.366 & 94 & 471 & 6 & 7.837 & 100 & \\
\hline No & 13.102 & 94,1 & 818 & 5,9 & 13.920 & 100 & \\
\hline Total & 20.468 & 94,1 & 1.289 & 5,9 & 21.757 & 100 & 0.689 \\
\hline
\end{tabular}

Source: own elaboration.

people per room, and a floor predominantly made of cement. This finding is consistent with the study by Krieger and Higgins, who reported that poor housing conditions were associated with health conditions, including the transmission of TB (Krieger \& Higgins 2002).

Daza Arana (2013) concluded that the socioeconomic context influences the prevalence of RS and suggested that efficient methodologies of community-based research, based upon the specific characteristics of each territory, could be developed to further enhance the detection of RS (Daza Arana 2013). The author also found that a moderate level of food insecurity was associated with a greater risk of RS. Henao et al. (1999) also found that poor diet was associated with RS. The results of our study relating to nutrition conditions indicate that participants lacking vegetables in their diet had an increased risk of RS, while the lack of consumption of cereals proved to be a protective factor for the development of symptoms. Our study examined a low-income population; this finding may reflect the prevalent type of diet in this population. An example of this is the finding that the proportion of participants with RS was higher among those who did not practice hunting or fishing to obtain nutrition.

Freitas et al. (2011) found that RS was associated with lower socioeconomic status, as indicated by the lower income level in this population. The increased risk of RS was also associated with a lower level of education. The authors suggested that populations with low socioeconomic status have less access to health services (Freitas et al. 2011). Socioeconomic status and educational level may influence care seeking and attendance at health services. A study in Brazil found that barriers to access to health services in indigenous population influenced the presence of RS, as individuals were less likely to seek medical care (Nóbrega et al. 2010). In our study, the types of housing and home heating increased the risk of having symptoms. However, additional studies are necessary to investigate how socioeconomic factors contribute to increased incidence of RS.

The risk of RS among those with a family history of TB is indicative of disease transmission in this population. Moreover, after ethnic group, family history was the variable with the most significant impact on the increased risk of symptoms. Finally, in our study, female sex and older age were associated with a higher prevalence of RS. However, other studies have reported male sex to be a risk factor for RS. Our findings may be explained by the fact that the women in our study spent more time at home than did the men. In addition, indigenous women tend to minimise their symptoms and therefore delay seeking care (Thorson et al. 2004, WHO 2004). Women also act as the caregivers of the family, particularly for their children; because of their role in the household economy, women may consider the health of other household members before their own, as well as prioritising the family economy above any personal expenses. The finding of age as a risk factor is consistent with previous research (García et al. 2004). In this sense, the results of our study are consistent with other evidence suggesting that the risk of respiratory symptoms and developing TB increases with age.

Considering the small number of confirmed TB cases and the indicators of sensitivity and specificity, it is worth studying the factors. A systematic review of the sensitivity and specificity of questioning individuals regarding the presence of symptoms for the detection of bacteriologically confirmed active pulmonary TB in HIV-negative persons and persons with unknown HIV status considered eligible for TB screening revealed eight studies that provided data on 'any TB symptom' as a screen for symptomatic status. The number and duration of each symptom that qualified as a positive status differed across studies, ranging from four to eight symptoms. Cough, haemoptysis, fever, night sweats and weight loss were the most common (Tollefson et al. 2013). Thus, the results of our study are consistent with those of previous analyses, confirming that the presence of various symptoms in RS, particularly cough lasting three or more weeks, was the most frequent symptom.

This study has several limitations. In view of the small number of TB cases detected, it was not possible to examine the socioeconomic factors associated with TB. In addition, due to the complexity of the fieldwork and process of data collection in these communities, there was some loss of information and missing data. However, this does not imply a non-response bias in our study.

Our findings also trigger some reflections. Several variables across the different levels were significant in themselves. The fact that several factors individually and in context were associated with RS in the regression analysis shows that the prevalence of RS is socially determined and associated with poor living conditions. Further re- 
TABLE III

Mode of obtaining food (level 3) and type of feeding (level 4), Paraguay, 2012

\begin{tabular}{|c|c|c|c|c|c|c|c|}
\hline \multirow[b]{3}{*}{ Characteristics } & \multicolumn{6}{|c|}{ Respiratory symptomatic } & \multirow[b]{3}{*}{ p-value } \\
\hline & \multicolumn{2}{|c|}{ No } & \multicolumn{2}{|c|}{ Yes } & \multicolumn{2}{|c|}{ Total } & \\
\hline & $\mathrm{n}$ & $(\%)$ & $\mathrm{n}$ & $(\%)$ & $\mathrm{N}$ & $(\%)$ & \\
\hline \multicolumn{8}{|l|}{ Own cultivation } \\
\hline Yes & 9.025 & 94,6 & 520 & 5,4 & 9545 & 100 & \\
\hline No & 12.411 & 93,8 & 825 & 6,2 & 13236 & 100 & \\
\hline Total & 21.436 & 94,1 & 1.345 & 5,9 & 22781 & 100 & 0.013 \\
\hline \multicolumn{8}{|l|}{ Hunting or fishing } \\
\hline Yes & 4.388 & 95,5 & 205 & 4,5 & 4593 & 100 & \\
\hline No & 16.372 & 93,7 & 1.099 & 6,3 & 17471 & 100 & \\
\hline Total & 20.760 & 94,1 & 1.304 & 5,9 & 22064 & 100 & $<0.001$ \\
\hline \multicolumn{8}{|l|}{ Purchasing food } \\
\hline Yes & 22.257 & 94,4 & 1.316 & 5,6 & 23573 & 100 & \\
\hline No & 604 & 92,1 & 52 & 7,9 & 656 & 100 & \\
\hline Total & 22.861 & 94,4 & 1.368 & 5,6 & 24229 & 100 & 0.010 \\
\hline \multicolumn{8}{|c|}{ Daily frequency of food consumption } \\
\hline Once a day & 2.007 & 92,7 & 159 & 7,3 & 2166 & 100 & \\
\hline Twice per day & 5.513 & 94,1 & 345 & 5,9 & 5858 & 100 & \\
\hline Three times per day & 14.992 & 94,7 & 845 & 5,3 & 15837 & 100 & \\
\hline Four times a day & 352 & 94,1 & 22 & 5,9 & 374 & 100 & \\
\hline Five times a day & 21 & 80,8 & 5 & 19,2 & 26 & 100 & \\
\hline More than 5 times & 16 & 88,9 & 2 & 11,1 & 18 & 100 & \\
\hline Total & 22.901 & 94,3 & 1.378 & 5,7 & 24279 & 100 & $<0.001$ \\
\hline \multicolumn{8}{|c|}{ Consumption of vegetables } \\
\hline Yes & 19.756 & 94,4 & 1.169 & 5,6 & 20925 & 100 & \\
\hline No & 2.695 & 93,2 & 197 & 6,8 & 2892 & 100 & \\
\hline Total & 22.451 & 94,3 & 1.366 & 5,7 & 23817 & 100 & 0.008 \\
\hline \multicolumn{8}{|c|}{ Consumption of green vegetables } \\
\hline Yes & 18.783 & 94,9 & 1.009 & 5,1 & 19792 & 100 & \\
\hline No & 3.755 & 91,1 & 365 & 8,9 & 4120 & 100 & \\
\hline Total & 22.538 & 94,3 & 1.374 & 1,5 & 23912 & 100 & $<0.001$ \\
\hline \multicolumn{8}{|l|}{ Consumption of cereals } \\
\hline Yes & 20.024 & 94,1 & 1.253 & 5,9 & 21277 & 100 & \\
\hline No & 2.554 & 95,6 & 117 & 4,4 & 2671 & 100 & \\
\hline Total & 22.578 & 94,3 & 1.370 & 5,7 & 23948 & 100 & 0.002 \\
\hline \multicolumn{8}{|l|}{ Consumption of fruit } \\
\hline Yes & 13849 & 94,4 & 817 & 5,6 & 14.666 & 100 & \\
\hline No & 8041 & 93,8 & 534 & 6,2 & 8.575 & 100 & \\
\hline Total & 21890 & 94,2 & 1.351 & 5,8 & 23.241 & 100 & 0.039 \\
\hline \multicolumn{8}{|l|}{ Consumption of meat } \\
\hline Yes & 19288 & 94,7 & 1.085 & 5,3 & 20.373 & 100 & \\
\hline No & 3127 & 91,7 & 283 & 8,3 & 3.410 & 100 & \\
\hline Total & 22415 & 94,2 & 1.368 & 5,8 & 23.783 & 100 & $<0.001$ \\
\hline \multicolumn{8}{|c|}{ Consumption of dairy products } \\
\hline Yes & 12819 & 95 & 670 & 5 & 13.489 & 100 & \\
\hline No & 9109 & 93,1 & 670 & 6,9 & 9.779 & 100 & \\
\hline Total & 21928 & 94,2 & 1.340 & 5,8 & 23.268 & 100 & $<0.001$ \\
\hline \multicolumn{8}{|l|}{ Receiving food donations } \\
\hline Yes & 1.847 & 95,9 & 79 & 4,1 & 1926 & 100 & \\
\hline No & 18.662 & 93,9 & 1.213 & 6,1 & 19875 & 100 & \\
\hline Total & 20.509 & 94,1 & 1.292 & 5,9 & 21801 & 100 & $<0.001$ \\
\hline
\end{tabular}

Source: own elaboration. 
TABLE IV

Univariate and multivariate analysis of the characteristics associated with the prevalence of respiratory symptoms among the indigenous population of Paraguay, by level and hierarchical final model

\begin{tabular}{|c|c|c|c|c|c|c|c|c|c|c|}
\hline \multirow[b]{2}{*}{ Characteristics } & \multirow[b]{2}{*}{$(\%)$} & \multicolumn{3}{|c|}{ Univariate analysis by level } & \multicolumn{3}{|c|}{ Multivariate analysis by level } & \multicolumn{3}{|c|}{ Final Multivariate analysis } \\
\hline & & PR & $95 \% \mathrm{CI}$ & $\mathrm{p}$-value & PR & $95 \% \mathrm{CI}$ & p-value & PR & $95 \% \mathrm{CI}$ & p-value \\
\hline \multicolumn{11}{|l|}{ LEVEL 1} \\
\hline \multicolumn{11}{|l|}{ Age } \\
\hline $0-37$ years & 63,7 & & & & & & & & & \\
\hline$\geq 38$ years & 36,3 & 2.21 & $2.09-2.63$ & $<0.001$ & 2.16 & $1.93-2.41$ & $<0.001$ & 1.85 & $1.60-2.09$ & $<0.001$ \\
\hline \multicolumn{11}{|l|}{ Sex } \\
\hline Male & 44,2 & & & & & & & & & \\
\hline Female & 55,8 & 1.32 & $1.21-1.50$ & $<0.001$ & 1.32 & $1.18-1.46$ & $<0.001$ & 1.33 & $1.19-1.50$ & $<0.001$ \\
\hline \multicolumn{11}{|l|}{ Education level } \\
\hline Until EEB level 1 and 2 & 55,5 & & & & & & & & & \\
\hline EEB level 3 or more & 44,5 & 0.79 & $0.71-0.88$ & $<0.001$ & 0.86 & $0.77-0.96$ & 0.008 & 2.43 & $2.04-2.94$ & $<0.001$ \\
\hline \multicolumn{11}{|l|}{ LEVEL 2} \\
\hline \multicolumn{11}{|l|}{ Family history of TB } \\
\hline No & 88,9 & & & & & & & & & \\
\hline Yes & 11,1 & 3.57 & $2.94-4.16$ & $<0.001$ & 3.33 & $2.77-4.00$ & $<0.001$ & & & \\
\hline \multicolumn{11}{|l|}{ Type of housing } \\
\hline House/Rancho & 83,1 & & & & & & & & & \\
\hline Makeshift shelter & 16,9 & 1.52 & $1.32-1.75$ & $<0.001$ & 1.25 & $1.07-1.46$ & 0.004 & 1.19 & $1.02-1.39$ & $<0.001$ \\
\hline \multicolumn{11}{|l|}{ Type of health service } \\
\hline Bath water trawl (network / well) & 1,8 & & & & & & & & & \\
\hline Other (Community, stream, river) & 97,2 & 1.60 & $1.08-2.39$ & 0.018 & & & & & & \\
\hline \multicolumn{11}{|l|}{ Availability of heating at home } \\
\hline Yes & 41,5 & & & & & & & & & \\
\hline No & 58,5 & 1.34 & $1.20-1.49$ & $<0.001$ & 1. 39 & $1.24-1.57$ & $<0.001$ & 1.34 & $1.19-1.51$ & $<0.001$ \\
\hline \multicolumn{11}{|l|}{ TV access at home } \\
\hline Yes & 31,8 & & & & & & & & & \\
\hline No & 68,2 & 1.58 & $1.41-1.78$ & $<0.001$ & 1.38 & $1.21-1.58$ & $<0.001$ & 1.33 & $1.19-1.55$ & $<0.001$ \\
\hline \multicolumn{11}{|l|}{ Use of a a horse, donkey, ox? } \\
\hline Yes & 2,4 & & & & & & & & & \\
\hline No & 97,6 & 1.77 & $1.24-2.53$ & 0.002 & 1.58 & $1.11-2.27$ & 0.011 & & & \\
\hline \multicolumn{11}{|l|}{ Cooking method } \\
\hline Firewood & 88,4 & 1.50 & $1.28-1.77$ & $<0.001$ & 1.29 & $1.07-1.55$ & 0.006 & & & \\
\hline Other & 11,6 & & & & & & & & & \\
\hline \multicolumn{11}{|l|}{ LEVEL 3} \\
\hline \multicolumn{11}{|l|}{ Receiving food donations } \\
\hline Yes & 6,1 & & & & & & & & & \\
\hline No & 93,9 & 1.48 & $1.18-1.86$ & 0.001 & 1.43 & $1.12-1.81$ & 0.004 & & & \\
\hline \multicolumn{11}{|l|}{ Own cultivation } \\
\hline Yes & 38,7 & & & & & & & & & \\
\hline No & 61,3 & 1.14 & $1.02-1.27$ & 0.016 & & & & & & \\
\hline Hunting or fishing & & & & & & & & & & \\
\hline Yes & 15,7 & & & & & & & & & \\
\hline No & 84,3 & 1.40 & $1.21-1.63$ & $<0.001$ & 1.36 & $1.16-1.59$ & $<0.001$ & 1.30 & $1.11-1.53$ & 0.001 \\
\hline Purchasing food & & & & & & & & & & \\
\hline Yes & 96,2 & & & & & & & & & \\
\hline No & 3,8 & 1.41 & $1.07-1.87$ & 0.015 & 1.59 & $1.19-2.12$ & 0.001 & 1.46 & $1.10-1.93$ & 0.009 \\
\hline
\end{tabular}


Univariate analysis by level Multivariate analysis by level Final Multivariate analysis

\begin{tabular}{|c|c|c|c|c|c|c|c|c|c|c|}
\hline \multirow[b]{2}{*}{ Characteristics } & \multirow[b]{2}{*}{$(\%)$} & & & \\
\hline & & PR & $95 \% \mathrm{CI}$ & $\mathrm{p}$-value & PR & $95 \% \mathrm{CI}$ & $\mathrm{p}$-value & PR & $95 \% \mathrm{CI}$ & $\mathrm{p}$-value \\
\hline \multicolumn{11}{|l|}{ LEVEL 4} \\
\hline \multicolumn{11}{|c|}{ Consumption of green vegetables } \\
\hline Yes & 0,3 & & & & & & & & & \\
\hline No & 99,7 & 1.73 & $1.54-1.95$ & $<0.001$ & 1.63 & $1.42-1.86$ & $<0.001$ & 1.22 & $1.07-1.74$ & 0.003 \\
\hline \multicolumn{11}{|c|}{ Consumption of cereals } \\
\hline Yes & 91,5 & & & & & & & & & \\
\hline No & 8,5 & 0.74 & $0.61-0.89$ & 0.003 & 0.69 & $0.57-0.84$ & $<0.001$ & 0.72 & $0.59-0.89$ & 0.001 \\
\hline \multicolumn{11}{|c|}{ Consumption of fruit } \\
\hline Yes & 60,5 & & & & & & & & & \\
\hline No & 39,5 & 1.11 & $1.01-1.24$ & 0.045 & 0.82 & $0.72-0.94$ & 0.004 & & & \\
\hline \multicolumn{11}{|c|}{ Consumption of meat } \\
\hline Yes & 79,3 & & & & & & & & & \\
\hline No & 23,6 & 1.55 & $1.36-1.77$ & $<0.001$ & 1.38 & $1.19-1.60$ & $<0.001$ & & & \\
\hline \multicolumn{11}{|c|}{ Consumption of dairy products } \\
\hline Yes & 50 & & & & & & & & & \\
\hline No & 50 & 1.37 & $1.23-1.53$ & $<0.001$ & 1.22 & $1.08-1.39$ & 0.001 & & & \\
\hline \multicolumn{11}{|c|}{ Etnia Ayoreo/Manjui } \\
\hline No & 84,6 & & & & & & & & & \\
\hline Yes & 15,4 & & & & & & & 3.25 & $2.75-3.85$ & $<0.001$ \\
\hline
\end{tabular}

CI: confidence interval. Source: own elaboration.

search is needed in order to better understand the association between the prevalence of RS, the underlying social and economic context, and the individual characteristics of participants, as well as to evaluate the relative contribution of each of these factors with the increased prevalence of RS among indigenous populations in Paraguay.

In conclusion, the findings of our study indicate that individual factors, dietary habits, and ethnic groups were associated with an increased prevalence of RS among indigenous populations in Paraguay. The detection of symptoms could enable the identification of targeted actions, optimisation of resources, and elaboration of long and short-term policies to reduce the prevalence of TB and contribute to disease control. Finally, the ethnic groups with higher prevalence are not explained by the current literature but offer a valuable finding for later investigations to elucidate why the RS differ in these indigenous groups.

\section{ACKNOWLEDGEMENTS}

To the Tuberculosis Control Program of Paraguay, to Breanne Nicole Lesnar, for her invaluable contribution in the translation of this paper, and to all of the participants for sharing their stories and making this study possible.

\section{AUTHORS' CONTRIBUTION}

SA, CM, GCC, NG and MA - Responsible for the final review of the protocol design and the writing of the manuscript; $\mathrm{MBH}$ - participated in the protocol design, data analysis and responsible for the manuscript preparation; JUB - participated in the protocol design, data analysis and writing of the manuscript, mainly responsible for the final manuscript review.

\section{REFERENCES}

AFN - Assembly of First Nations. A global indigenous peoples'. Initiative to Stop TB: our children, our future. Assembly of First Nations Inuit Tapiriit Kanatami. Toronto: 2009; 17 pp.

Barry C, Konstantinos A. Tuberculosis notifications in Australia, 2007. Commun Dis Intell Q Rep. 2009; 33(3): 304-15.

CDC - Centers for Disease Control. Decrease in reported tuberculosis cases - United States, 2009. MMWR Morb Mortal Wkly Rep. 2010; 59(10): 289-94.

Collazos C, Carrasquilla G, Ibáñez M, López LE. Prevalencia de sintomáticos respiratorios en instituciones prestadoras de servicios de salud de Bogotá, D.C., junio de 2005 a marzo de 2006. Biomedica. 2010; 30(4): 519-29.

Culqui DR, Trujillo OV, Cueva N, Aylas R, Salaverry O, Bonilla C. Tuberculosis en la población indígena del Perú 2008. Rev Peru Med Exp Salud Publica. 2010, 27(1): 278-315.

Das D, Baker M, Calder L. Tuberculosis epidemiology in New Zealand: 1995-2004. N Z Med J. 2006; 119(1243): U2249.

Daza Arana JE. Prevalencia de sintomáticos respiratorios y factores relacionados en los residentes de dos territorios vulnerables de la ciudad de Santiago de Cali, año 2012 [Tesis de Maestria]. Cali: Universidad del Valle; 2013.

DGEEC - Dirección General de Estadística, Encuestas y Censos. II Censo Nacional Indígena 2002 [homepage on the Internet]. 2012 Available from: http://www.dgeec.gov.py/Publicaciones/Biblioteca/censo indigena 2012/Pueblos indigenas en el Paraguay Resultados preliminares.

Fanning A. Tuberculosis: 1. Introduction. CMAJ. 1999; 160(6): 837-9. 
Fitzgerald JM, Wang L, Elwood RK. Tuberculosis: 13. Control of the disease among aboriginal people in Canada. CMAJ. 2000; 162(3): 351-5.

Freitas FTM, Yokota RTC, Castro APB, Andrade SSCA, Nascimento GL, Moura NFO, et al. Prevalência de sintomáticos respiratórios em regiões do Distrito Federal, Brasil. Rev Panam Salud Publica. $2011 ; 29(6): 451-6$.

García I, De la Hoz F, Reyes Y, Montoya P, Guerrero MI, León CI. Prevalencia de sintomáticos respiratorios, de infección y enfermedad tuberculosa y factores asociados: estudio basado en población, Mitú, Vaupés, 2001. Biomedica. 2004; 24(Suppl. 1): 124-31.

Hargreaves JR, Boccia D, Evans CA, Adato M, Petticrew M, Porter JD. The social determinants of tuberculosis: from evidence to action. Am J Public Health. 2011; 101(4): 654-62.

Henao G, De la Hoz F, León C, Ribón W, Guerrero M. Epidemiología clásica y molecular de la tuberculosis en el Guaviare 1997-1998. Informe Quincenal Epidemiológico Nacional. 1999; 4: 85-91.

Hoeppner VH, Marciniuk DD. Tuberculosis in aboriginal Canadians. Can Respir J. 2000; 7(2): 141-6.

Krieger J, Higgins DL. Housing and health: time again for public health action. Am J Public Health. 2002; 92(5): 758-68.

Lopez PA, Fernández PV, Morel IM. Prevalencia de tuberculosis en indígenas del departamento de Itapúa. Asunción. 2013.
Moreno LL, Peña CET. Prevalencia de sintomáticos respiratorios y tuberculosis en la población en condición de desplazamiento, Bucaramanga, 2007. MedUNAB. 2010; 13(2): 75-80.

Muniyandi M, Ramachandran R, Gopi PG, Chandrasekaran V, Subramani $\mathrm{R}$, Sadacharam $\mathrm{K}$, et al. The prevalence of tuberculosis in different economic strata: a community survey from South India. Int J Tuberc Lung Dis. 2007; 11(9): 1042-5.

Nóbrega RG, Nogueira JA, Netto AR, Sá LD, Silva ATMC, Villa TCS. The active search for respiratory symptomatics for the control of tuberculosis in the Potiguara indigenous scenario, Paraíba, Brazil. Rev Lat Am Enfermagem. 2010; 18: 1169-76.

Thorson A, Hoa NP, Long NH, Allebeck P, Diwan VK. Do women with tuberculosis have a lower likelihood of getting diagnosed? Prevalence and case detection of sputum smear positive pulmonary TB, a population-based study from Vietnam. J Clin Epidemiol. 2004; 57(4): 398-402.

Tollefson D, Bloss E, Fanning A, Redd JT, Barker K, McCray E. Burden of tuberculosis in indigenous peoples globally: a systematic review. Int J Tuberc Lung Dis. 2013; 17(9): 1139-50.

UN - United Nations. State of the world's indigenous peoples. New York: 2012.

WHO - World Health Organization. Tuberculosis. Gender in tuberculosis research. WHO. 2004; 46 pp. Available from: http://apps. who.int/iris/bitstream/10665/43085/1/9241592516.pdf. 